\title{
Pradhan Mantri Jan Arogya Yojana - Ayushman Bharat
}

Vinoth Gnana Chellaiyan ${ }^{1}$, Hanitha Rajasekar ${ }^{2}$, Neha Taneja ${ }^{3}$

${ }^{1}$ Assistant Professor, Department of Community Medicine, Chettinad Hospital \& Research Institute, Chettinad Academy of Research \& Education, Kelambakkam, Chennai, Tamil Nadu, India; ${ }^{2}$ Post graduate, Department of Community Medicine, Chettinad Hospital \& Research Institute, Chettinad Academy of Research \& Education, Kelambakkam, Chennai, Tamil Nadu, India; ${ }^{3}$ Assistant Professor, Amity Institute of Public Health, Amity University, Noida, Uttar Pradesh

\begin{tabular}{|c|c|c|c|c|c|c|c|c|}
\hline Abstract & Introduction & Methodology & $\underline{\text { Results }}$ & Conclusion & $\underline{\text { References }}$ & Citation & \multicolumn{2}{|c|}{ Tables / Figures } \\
\hline \multicolumn{9}{|c|}{ Corresponding Author } \\
\hline \multicolumn{8}{|c|}{$\begin{array}{l}\text { Dr Vinoth Gnana Chellaiyan D, Assistant Professor, Department of Community Medicine, Chettinad Hospital } \\
\text { \& Research Institute, Chettinad Academy of Research \& Education, Kelambakkam, Chennai, Tamil Nadu. } \\
\text { E Mail ID: } \underline{\text { drchellaiyan@gmail.com }}\end{array}$} & 回评回 \\
\hline
\end{tabular}

\section{Citation}

Chellaiyan VG, Rajasekar H, Taneja N. Pradhan Mantri Jan Arogya Yojana - Ayushman Bharat. Indian J Comm Health. 2020;32(2):337- 340 .

\section{Article Cycle}

Source of Funding: Nil Conflict of Interest: None declared

\begin{abstract}
Received: 03/04/2020; Revision: 20/05/2020; Accepted: 07/05/2020; Published: 30/06/2020
This work is licensed under a Creative Commons Attribution 4.0 International License.

Abstract

Introduction: "Ayushman Bharat Initiative" also known as Pradhan Mantri Jan Arogya Yojana (PMJAY) was launched in 2018, by Government of India. The core principle of Ayushman Bharat - National health protection mission is co-operative federalism and flexibility to states. PMJAY encapsulates a progression towards promotive, preventive, palliative and rehabilitative aspects of Universal Health coverage through access of Health and Wellness Centre (HWCs) at the primary level and provisioning of financial protection for accessing curative care at the secondary and tertiary levels through engagement with both public and private sector. PMJAY covers 1350 medical packages including surgery and day care treatments, cost of medicines and diagnostics. It involved participation of centre and states, use of technology for administration of the scheme and involved participation of private sector hospitals and insurers to provide accessible and affordable healthcare by a large section of society. Aims and objectives: The objective of this review is to explore the PMJAY program and to assess how far it could achieve the goal of universal health coverage. Conclusion: It is a major step by Government of India to fulfil the goal of universal health coverage hence if implemented properly it could be a game changer.
\end{abstract}

\section{Keywords}

Insurance; Health; Universal Health Insurance

\section{Introduction}

"Ayushman Bharat Initiative" also known as Pradhan Mantri Jan Arogya Yojana (PMJAY) was launched in 2018, by Government of India. It encapsulates a progression towards promotive, preventive, palliative and rehabilitative aspects of Universal Health coverage through access of Health and Wellness Centre (HWCs) at the primary level and provisioning of financial protection for curative care at the secondary and tertiary levels through engagement with public and private sector(1). It covers over 10 crores poor families providing up to 5 lakhs rupees per annum per family. This initiative should improve the access to quality health services and help fulfilling Government's goal to build a new India by 2022 supplementing its economic progress(2). The core principles of Ayushman Bharat is co-operative federalism and flexibility to states. Union Health and Family Welfare
Minister is responsible for policy directions and foster coordination between Centre and States. State health agency ensures that funds reach on time through Escrow account directly. In partnership with NITI Aayog, a robust modular IT platform was operational for paperless and cashless transaction(3). The objective of this review is to explore the PMJAY program and to assess how far it achieves the goal of universal health coverage.

\section{Inclusion and exclusion criteria}

PMJAY covers nearly 1350 medical packages including surgery and day care treatments, cost of medicines and diagnostics(4). There are various criteria listed out for selecting the beneficiaries according by National health agency. Households without shelter, people living on alms, Manual scavenger families and Primitive tribal groups are automatically included under this scheme. As per the SECC 2011, beneficiaries automatically excluded 
are, Households having motorized 2/3/4 wheeler/fishing boat, mechanized 3/4 wheeler agricultural equipment, kisan Credit Card with credit limit above Rs. 50,000/, government employee, income tax payees, member of household earning more than Rs. 10,000/- per month(5 )

\section{Steps in PMJAY:}

Eligibility: Very first step in the scheme is to check for eligibility. This process is done by Empanelled health care providers registration desk through 'Am I Eligible' app or website or through call centre number 14555

Patient card: After the eligibility process is over patient will be directed to PMJAY Kiosk where Pradhan Mantri Arogya Mitra will help in verifying the beneficiary identity by using Beneficiary Identification System (BIS). If e-card is not available then golden record will be created. The required documents for Ayushman Bharat include Age proof document, identification details, contact information, family structure, income certificate, caste certificate. Aadhar card and PAN card is source of identification under the scheme. Person belonging to reserved category will get benefits based on prescribed annual income criteria I.e. maximum income being 5 lakh per year(6).

Expenses: Pradhan Mantri Arogya Mitra will then inform the beneficiaries about the scheme and ex-penses which the beneficiary has to bear in case he/ she is not hospitalised.

Beneficiary is then directed to doctor for treatment of the disease ailment. Beneficiary is either pre-scribed drugs or hospitalised depending on the severity of the disease. The beneficiary if admitted it is the responsibility of doctor to provide necessary documents to PMAM and the Arogya Mitra will up-load the documents with Transaction Management System Portal for Government verification. Post treatment medications will be provided by the hospital unto 15 days as applicable(7).

\section{Past accomplishments in India}

In first 100 days the program has been utilised by 6.85 lakh patients and among them 5.1 lakh received the payment. Many people from weaker sections had avoided treatment in view of unbearable payment but now $40 \%$ of India's poorest are assured treatment at the cost of public expenditure. Gujarat is top performer among the states rolling out the scheme with 76000 hospital admissions and second place goes to Tamil Nadu with 54,273 admissions as per health ministry data as of February 2019(8). Railway ministry has shown interest in joining PMJAY and have empaneled ninety-three hospitals to provide free treatment of PMJAY Beneficiaries and this will ensure additional 10000 beds and 2000 doctors to provide services. A visit was also arranged to AlIMS, New Delhi to make hospital staffs to expose themselves in operation of Arogya Mitra Sahayata Kendra(9). Ayushman Bharat scheme has lead to timely treatments, improvements in health outcomes, patient satisfaction, improvement in productivity and efficiency, job creation thus, leading to an improvement in the quality of life(10).

\section{Critical appraisal:}

The scheme endeavors to provide healthcare services to a large section of society who otherwise cannot afford them hence if implemented properly it could be a game changer. The Problem of shortage of human resource needs to be addressed on a priority basis else public sector health care will remain of poor quality and become largely unacceptable, forcing patients to go to the private sector. This gives an impression that NHPS scheme was designed to benefit private parties more than government health services. This will ultimately be unsustainable and even detrimental for the poor for whom the scheme is intended. However, Government of India had set a target of appoint-ing 1 lakh Arogya mitras by end of 2018 to carryout PMJAY scheme. There will be a lack of health care workers to work on 50 crore beneficiaries if this target is not achieved on time(11).

For the success of any health program, outpatient services must be given due importance but PMJAY covers only secondary and tertiary level of hospitalization raising question on the success of the program. On an average a physician will be able to see $30-40$ out-patients in a day according to a recent survey. National health mission 2014-2015 has estimated OOPE for out-patient services as 1281.08 per capita per year(12).

Another demerit is that beneficiaries included are BPL families who lack adequate knowledge about beneficiary identification system until otherwise assisted and community participation should be encouraged. Identification of beneficiaries can be done by linking with Aadhar and similarly following up for services received and health outcomes achieved, thereby helping to monitor and evaluate the impact of the programme(13). Suitable and uniform pricing system must be derived for various health interventions, including diagnostics and medicines, displaying them in hospital premises ensuring the transparency of such a scheme. At National level, Only Empowered Action Group (EAG) states where there was no appropriate health insurance scheme like Bihar, Jharkhand, Odisha, Assam, UP, MP, Rajasthan, Chattisgarh will be benefitted more by PMJAY scheme (14). Lastly middle class population has not been included by most of the government aided programs including PMJAY and it is important to include them as they lie at the edge of sword in terms of any such health insurance schemes. The scheme envisages to see a laborer from a village being able to walk into a hospital for an angioplasty without having to pay to the hospital and with increased investment in health. 


\section{SWOT Analysis:(11)}

\section{Strength:}

1. Focus of government initiatives to comprehensive primary health care rather than disease specific and reproductive and child health.

2. It makes us realise that economic growth of India depends on better health.Target beneficiaries have increased significantly with social sector program expanded to vulnerable and deprived population rather poor only population.

3. Health conditions like mental health, noncommunicable diseases, food and internal congenital dis-eases not addressed before have been given due emphasis in the scheme.

4. Provides both global and national level focus on Universal health coverage.

\section{Weakness:}

1. The focus on broader health system is minimally addressed. Strengthening entire health system is required than concentrating only on Health and wellness centres.

2. Major part of OOPE constitutes preventive and/or outpatient care however scheme will provide coverage only for secondary and tertiary care hospitalisation.

3. Inadequate Funds allocated for setting up Health and Wellness Centres (HWC's). Budget allocation of 1200 crores for setting up and upgrading 1.5 lakh, HWC's centres to cater to medical treatment need appears to be grossly inadequate.

4. By putting no limitation on age of beneficiaries and including pre-existing diseases from first day onwards hints at a faulty coverage proposed in the scheme putting undue pressure on insurance companies.

5. Little effort or investment to develop a wellcoordinated referral mechanism with specialists and doctors in the secondary and tertiary hospitals which shall be the cornerstone of the project.

\section{Opportunities:}

1. More chance of strengthening entire health care system in India with novel models and strategies.

2. Experience gained from RSBY and other such schemes could be utilised for a rapid growth.

3. Implementation will be accelerated since this program has wide public and media attention.

4. Recruitment of additional cadre of health providers on priority basis thus giving employment opportunities.

5. Generate real time data and analyze it to further strengthen existing schemes.

6. Allignment with NHP 2017 and NitiAyogs 3 year action agenda 2017-20.(36)
Threats:

[Pradhan Mantri Jan...] | Chellaiyan VG et al

1. Chance of changes in the political leadership poses a major threat to the program.

2. Focus is not proportionate on one of two initiatives in $A B P$.

3. Lack of human resource for setting up of $\mathbf{1 5 0 0 0 0}$ HWC's.

4. Lack of regulatory mechanism to monitor the quality of service being provided by private hospital, its ethical necessity and whether the patient was made to pay more than what the scheme covered.

5. Government hospitals lacking infrastructure will also chip in thus compromising the aim to ensure accessible and affordable healthcare.

6. Too much engagement of private hospitals to provide financial cover will reinforce the impression that private healthcare is better than government healthcare.

7. Strict monitoring between State Health Insurance Schemes and Ayushman Bharat required as state would try to reduce their financial burden by pushing patients through this scheme.

\section{Recent advances in scheme:}

Ayushman Bharat is on the urge to strengthen its health initiative by integrating traditional medical therapy with allopathy at public health centres (PHCs) in a big way to arrest rising chronic non-communicable diseases like diabetes and obesity. To prevent rising chronic lifestyle diseases, The Ayush Ministry is in the process of identifying 12,500 health and wellness centres across countries for rendering Ayush services at the root level with special reference to preventive health care(15).

\section{Conclusion}

Universal Health Coverage has become a key guiding target of health care across the world under Sustainable development goals to improve health of the global population and to overcome the scourge of medicalrelated impoverishment(16). PMJAY can be a success if funds are being managed appropriately and quality care is assured to the beneficiaries under the scheme. Both public and private sector should work hand in hand to carry the scheme forward. Health insurance schemes like these are essential in the developing world with new diseases being encountered on regular basis.

\section{Recommendation}

PMJAY focus on comprehensive primary health care rather than disease specific and reproductive and child health. Lessons from successful countries and strategies such as prior experimentation, pay-for-performance, good information system \& strong verification process could be followed to achieve the goal of universal health care affordable to all. 


\section{Relevance of the study}

It is estimated that $62.6 \%$ of total health expenditure in India (2.4\% of GDP, Rs. 2394 per capita) by household is out of pocket expenditure for health related events. People having no access to any form of health insurance scheme are being forced to make OOPE which has pushed nearly 39 million Indians to poverty each year and still only $15 \%$ of the population is protected by medical care insurance coverage.

\section{Authors Contribution}

All authors have contributed equally.

\section{References}

1. Ayushman Bharat for a New India-2022, Announced. Press Information Bureau, Governement of India, Department of Finance.[Homepage on internet]. Available from: http://www.pib.nic.in/newsite/PrintRelease.aspx?relid=176049.

2. Is Ayushman Bharat a game changer? [Homepage on Internet]. Opinion news;. Available from: https://indianexpress.com

3. Ayushman Bharat - National health protection mission/ National portal of India. [Homepage on Internet]. Available from: https://www.india.gov.in>spotlight

4. Ayushman Bharat Yojana [Homepage on Internet].[cited 2019 July 19]. Available from: www.nap.gov.in

5. PMJAY recruitment: NHA makes important clarification on hiring of Arogyamitras [Homepage on Internet].Available from: www.financialexpress.com

6. PMJAY Ayushman Bharat Yojna / National health protection scheme 2019: Registration, Beneficiary list \& hospital list.
[Homepage on Internet]. Available from: https://nvshq.org> scheme>pmjay

7. How to apply for Ayushman Bharat Yojana? - Jagran Josh. [Homepage on Internet]. Available from: https://m.jagranjosh.com>

8. Ayushman Bharat scheme averaged 5000 claims per day in first 100 days [Homepage on the Internet].Available from: www.businesstoday.in

9. Issue 6 April 2019 - Ayushman Bharat [Homepage on the Internet]. [cited 2019 July 15]. Available from: https://www.pmjay.gov.in>

10. Dhaka R, Verma R, Agrawal G, Kumar G. Ayushman Bharat Yojana: a memorable health initiative for Indians. Int J Community Med Public Health 2018;5:3152-3.

11. Lahariya C. 'Ayushman Bharat' Program and Universal Health Coverage in India. Indian Pediatr. 2018 Jun 15;55(6):495-506. Review. PubMed PMID: 29978817.[PubMed]

12. Is Ayushman Bharat a game changer? [Homepage on Internet]. Opinion News;. Available from: https://indianexpress.com

13. National health mission. [Homepage on Internet]. Household health expenditure in Indi;. [cited 2018 December 5].Available from: https://www.mohfw.gov.in/

14. Cabinet approves Ayushman Bharat ; National Health Protection. [Homepage on Internet]. Available from: www. pib.nic.in

15. PMJAY to push integration of Allopathy and Ayush. [Homepage on Internet]. Available from: www.theindianpractitioner.com

16. Angell BJ, Prinja S, Gupt A, Jha V, Jan S. The Ayushman Bharat Pradhan Mantri Jan Arogya Yojana and the path to universal health coverage in India: Overcoming the challenges of stewardship and governance. PLoS Med. 2019 Mar;16(3):e1002759. doi: 10.1371/journal.pmed.1002759. eCollection 2019 Mar. Review. PubMed PMID: 30845199; PubMed Central PMCID: PMC6405049.[PubMed] 